\title{
CMOS Compatible Electrode Materials Selection in Oxide-Based Memory Devices
}

\author{
V. Y.-Q. Zhuo, ${ }^{1, a)}$ M. Li, ${ }^{1}$ Y. Guo, ${ }^{2}$ W. Wang, ${ }^{1}$ Y. Yang, ${ }^{1}$ Y. Jiang, ${ }^{1}$ and J. Robertson ${ }^{3, a)}$ \\ ${ }^{1}$ Data Storage Institute (A*STAR), 2 Fusionopolis Way, Singapore 138634, Singapore \\ ${ }^{2}$ Rowland Institute at Harvard, Harvard University, Cambridge, Massachusetts 02142, USA \\ ${ }^{3}$ Department of Engineering, University of Cambridge, Cambridge CB2 1PZ, United Kingdom
}

Electrode materials selection guidelines for oxide-based memory devices are constructed from the combined knowledge of observed device operation characteristics, ab-initio calculations, and nanomaterial characterization. It is demonstrated that changing the top electrode material from $\mathrm{Ge}$ to $\mathrm{Cr}$ to $\mathrm{Ta}$ in the $\mathrm{Ta}_{2} \mathrm{O}_{5}$-based memory devices resulted in a reduction of the operation voltages and current. Energy Dispersed X-ray (EDX) Spectrometer analysis clearly shows that the different top electrode materials scavenge oxygen ions from the $\mathrm{Ta}_{2} \mathrm{O}_{5}$ memory layer at various degrees, leading to different oxygen vacancy concentrations within the $\mathrm{Ta}_{2} \mathrm{O}_{5}$, thus the observed trends in the device performance. Replacing the Pt bottom electrode material with $\mathrm{CMOS}$ compatible materials ( $\mathrm{Ru}$ and $\mathrm{Ir}$ ) further reduces the power consumption and can be attributed to the modification of the Schottky barrier height and oxygen vacancy concentration at the electrode/oxide interface. Both trends in the device performance and EDX results are corroborated by the ab-initio calculations which reveal that the electrode material tunes the oxygen vacancy concentration via the oxygen chemical potential and defect formation energy. This experimental-theoretical approach strongly suggests that the proper selection of CMOS compatible electrode materials will create the critical oxygen vacancy concentration to attain low power memory performance.

\footnotetext{
a) Authors to whom correspondence should be addressed. Electronic mails: victor-zhuo@dsi.a-star.edu.sg; jr214@cam.ac.uk
} 


\section{INTRODUCTION}

The field of material engineering is driven by the dependence of emerging and future technologies on the generation of economic methods that can enhance the performance of portable electronic devices beyond miniaturization. Metal oxide-based memories, such as the resistive random access memory (RRAM), with its fast switching speeds, high endurance, low energy consumption, and CMOS compatibility, has attracted much interest as its applications extends to high-end nonvolatile embedded memory for neuromorphic computing and the Internet of Things. ${ }^{1-5}$ An oxide-based RRAM device typically consists of an oxide layer sandwiched between top (TE) and bottom (BE) electrodes, where the memory effect occurs as insulator resistive switching (RS) between high and low resistance states driven by external electrical bias. Since oxygen vacancies, $\mathrm{V}_{\mathrm{O}}$, are the most common defects in metal oxides, it is widely accepted that the RS relies on the dynamic migration of $\mathrm{V}_{\mathrm{O}}$, whose distribution and concentration significantly affect the electrical resistance. ${ }^{6}$ Charge trapping and de-trapping, thermochemical reactions, and insulator-to-metal transition may also be involved since the origin of the RS phenomenon remains controversial. ${ }^{6}$ To improve the control of the RS behavior and reduce the power consumption, most studies are focused on engineering the sandwiched memory layer. However, extensive research to decipher the link between device RS characteristics and the electrode material, in conjunction with its interface to the oxide, is severely lacking. In fact, electrodes significantly affect the RS behavior and device performance through direct modification of the Schottky barrier height at the electrode/oxide interfaces and the $\mathrm{V}_{\mathrm{O}}$ density within the metal-insulator-metal structure. ${ }^{7,8}$ For instance, it has been shown that the RS performance in $\mathrm{ZrO}_{2}, \mathrm{NiO}, \mathrm{TiO}_{2}, \mathrm{HfO}_{2}$, and $\mathrm{Ta}_{2} \mathrm{O}_{5}$ memory devices can be

modified by various electrode material configurations. ${ }^{9-14}$ Usually, the TE material is chemically active so as to scavenge oxygen ions from the metal oxide to create a particular amount of $\mathrm{V}_{\mathrm{O}}$ essential for reliable RS, whereas the BE material tends to be inert. However, it is unclear precisely which basic physical and chemical properties of the electrode materials control the RS performance. Previous studies 
on the effect of oxygen-scavenging TE materials on a particular metal oxide tend to be based mainly on the standard Gibbs free energy of interfacial oxide formation. ${ }^{8,9,15}$ This is inadequate since other factors such as the interfacial reactions, metal work functions and redox reactivity (oxygen chemical potential) should also be included for a more extensive study. Moreover, less work is done on understanding the role of the $\mathrm{BE}$ and $\mathrm{Pt}$, which has serious etch issues with standard CMOS processes, is the most commonly used BE material. Thus, it is imperative to study the impact of the electrode material on $\mathrm{V}_{\mathrm{O}}$ formation and RS characteristics of oxide-based memory devices such that clear strategies can be developed for engineering the electrode/oxide interfaces to achieve low power and reliable RRAM performance without compromising CMOS compatibility.

Here, we systematically study the impact of different TE (Ta, Cr, and Ge) and BE materials (Ru, Pt, and Ir) on $\mathrm{Ta}_{2} \mathrm{O}_{5}$-based RRAM devices via a three-pronged approach involving device electrical measurements, nano-material characterizations and theoretical calculations. These electrode materials cover a wide range of chemical reactivities with oxygen. $\mathrm{Ta}_{2} \mathrm{O}_{5}$ is chosen as the memory material due to its superior RS performance such as good scalability down to $30 \mathrm{~nm},{ }^{16}$ fast switching speeds below 1 $\mathrm{ns},{ }^{2}$ and high endurance beyond $10^{10}$ cycles. $^{17}$ We show that different electrode materials scavenge oxygen from the $\mathrm{Ta}_{2} \mathrm{O}_{5}$ at different degrees, resulting in different $\mathrm{V}_{\mathrm{O}}$ concentrations in the $\mathrm{Ta}_{2} \mathrm{O}_{5}$ and distinct trends in the electrically derived RS parameters. Hitherto, various models have been proposed for $\mathrm{V}_{\mathrm{O}}$ filamentary switching mechanism. ${ }^{18-26}$ However, the understanding of the energetics of the $\mathrm{V}_{\mathrm{O}}$ and the correlation between the material properties and device performance remains limited. Here, we calculate the defect formation energies and oxygen chemical potentials of the $\mathrm{V}_{\mathrm{O}}$ for each electrode material used in the $\mathrm{Ta}_{2} \mathrm{O}_{5}$-based RRAM. In addition, we derive the Schottky barrier heights at the electrode $/ \mathrm{Ta}_{2} \mathrm{O}_{5}$ interface to correlate to the observed experimental and theoretical trends. These insights enable us to propose a unified model for RRAM electrode materials selection which can optimize device 
RS parameters with better performance, thus advancing the commercialization of metal oxide-based RRAM.

\section{EXPERIMENTS}

Fig. 1(a) shows a schematic of a $\mathrm{TE} / \mathrm{Ta}_{2} \mathrm{O}_{5} / \mathrm{BE}$ device structure whereas the cross-sectional transmission electron microscope (TEM) image in Fig. 1(b) shows a magnified view of the $\mathrm{TE} / \mathrm{Ta}_{2} \mathrm{O}_{5} / \mathrm{BE}$ stack where the $5 \mathrm{~nm}$ thick $\mathrm{Ta}_{2} \mathrm{O}_{5}$ film is sandwiched between $40 \mathrm{~nm}$ thick TE and $\mathrm{BE}$ films. The devices are fabricated according to the standard process flow in Fig. 1(c). Here, the $\mathrm{Ta}_{2} \mathrm{O}_{5}$ films are deposited by radio frequency sputtering of a nominally stoichiometric $\mathrm{Ta}_{2} \mathrm{O}_{5}$ target whereas the other films are prepared by direct current (DC) sputtering. All the devices have active dimensions of 1 $\mu \mathrm{m}^{2}$ with a $\mathrm{SiO}_{2}$ passivation scheme. To study the TE impact on the electrical performance, $\mathrm{TE} / \mathrm{Ta}_{2} \mathrm{O}_{5} / \mathrm{Pt}$ devices are fabricated with different TE materials ( $\mathrm{Ta}, \mathrm{Cr}$, and $\mathrm{Ge}$ ). Then, the Pt BE is replaced by CMOS compatible materials ( $\mathrm{Ir}$ and $\mathrm{Ru}$ ) to create the $\mathrm{Ta} / \mathrm{Ta}_{2} \mathrm{O}_{5} / \mathrm{BE}$ devices to study the impact of different BE materials. The DC current-voltage characteristics of the devices are measured at room temperature in air using the Keithley 4200 semiconductor parameter analyzer where bias is applied to the TE with the BE grounded. We use the TEM equipped with scanning TEM (STEM) mode and an energy dispersive X-ray spectroscopy (EDX) to perform composition characterization and to disclose the distribution of the oxygen element in the devices.

We employ the plan-wave pseudopotential code CASTEP to investigate the energetics of the atomic processes related to the materials selection. The PBE-style generalized gradient approximation is used to calculate exchange-correlation energy. The default ultra-soft pseudopotential is used with a cutoff energy of $400 \mathrm{eV}$. The defect structure is optimized with a residual force of $0.01 \mathrm{eV} / \mathrm{A}$. The amorphous $\mathrm{Ta}_{2} \mathrm{O}_{5}$ structure is obtained by quenching from equilibrium at $3000 \mathrm{~K}$ with ab-initio molecular 
dynamics. A 144-atom model is used for defect calculation while a 225-atom model is compared to verify that the size-effect is negligible.

\section{RESULTS AND DISCUSSION}

We investigate the effect of different TEs ( $\mathrm{Ta}, \mathrm{Cr}$, and $\mathrm{Ge}$ ) on the RS characteristics of the amorphous $\mathrm{Ta}_{2} \mathrm{O}_{5}$ thin films with the $\mathrm{TE} / \mathrm{Ta}_{2} \mathrm{O}_{5} / \mathrm{Pt}$ configuration. Initially, all the pristine cells are in high resistance states and an electrical forming process is required to activate the reversible RS behavior and trigger the cells from high to low resistance state. To prevent hard breakdown during forming, a $100 \mu \mathrm{A}$ compliance current, $\mathrm{I}_{\mathrm{CC}}$, is used. Fig. 2(a) shows the typical I-V characteristics of the three configurations with Ta, Cr, and Ge TEs. Reset process occurs when a negative RESET voltage, $\mathrm{V}_{\text {RESET, }}$ switches the cells from low to high resistance state whereas the set process is triggered by a positive SET voltage, $\mathrm{V}_{\mathrm{SET}}$. Since the reset and set processes are dependent on the voltage polarity, these RRAM cells exhibit bipolar RS characteristic. To analyze the trends in the RS parameters, ten cells are randomly selected for each $\mathrm{TE} / \mathrm{Ta}_{2} \mathrm{O}_{5} / \mathrm{Pt}$ configuration for the electroforming procedure. Then, each cell is subjected to 50 consecutive switching cycles and the average values of the RS parameters are recorded. Fig. 2(b) show the average values of the DC SET and RESET voltages of the TE/Ta $\mathrm{O}_{5} / \mathrm{Pt}$ devices. We observe a clear trend in which both operation voltages increase from the Ta TE based devices to the $\mathrm{Cr}$ and then the Ge TE memory devices. The Ta TE devices possess extremely low operation voltages, where the $\mathrm{V}_{\text {SET }}$ and $\mathrm{V}_{\text {RESET }}$ are significantly reduced by about $40 \%$ and $30 \%$ when compared to the $\mathrm{Cr}$ and Ge TE devices, respectively. Besides operation voltages, the reset current, $\mathrm{I}_{\mathrm{RESET}}$, is another important memory parameter that requires optimization as it will influence the power consumption which determines the memory density. ${ }^{27}$ The $\mathrm{I}_{\text {RESET }}$ is the specific current that corresponds to the $V_{\text {RESET }}$ when the device switches from low to high resistance state. Since $I_{\text {RESET }}$ is usually the absolute maximum current during each switching cycle, it is also regarded as the programming current. 
Analogous to the trends for the operation voltages, the mean $\mathrm{I}_{\mathrm{RESET}}$ increases from Ta to Cr to Ge TE, as seen in Fig. 2(c). The $\mathrm{Ta} / \mathrm{Ta}_{2} \mathrm{O}_{5} / \mathrm{Pt}$ devices show significant reductions of $78 \%$ and $83 \%$ in the $\mathrm{I}_{\mathrm{RESET}}$ as compared to the $\mathrm{Cr}$ and Ge TE devices, respectively.

We then evaluate the impact of the $\mathrm{BE}$ material by replacing the $\mathrm{Pt}$ in the $\mathrm{Ta} / \mathrm{Ta}_{2} \mathrm{O}_{5} / \mathrm{Pt}$ structure with two CMOS compatible metals, Ir and $\mathrm{Ru}$. Ta is used as the TE since the TE study has shown that the Ta TE devices yield the best performance. Bipolar RS is observed for all $\mathrm{Ta} / \mathrm{Ta}_{2} \mathrm{O}_{5} / \mathrm{BE}$ structures using $\mathrm{Ru}$, Pt, or Ir as BE as seen in Fig. 2(d). Data is collected using the same considerations mentioned in the TE study. We observe the same trend for both the operation voltages (Fig. 2(e)) and $\mathrm{I}_{\text {RESET }}$ (Fig. 2(f)) where they increase when the BE is changed from Ru to Pt to Ir. However, the improvements are of a lesser degree than that is observed in the TE study. Regarding the $\mathrm{V}_{\mathrm{SET}}$, the $\mathrm{Ru} \mathrm{BE}$ devices show reductions of $4 \%$ and $17 \%$ over the Pt and Ir BE devices, respectively. Similarly, the $\mathrm{V}_{\text {RESET }}$ of the Ru BE devices shows reductions of $5 \%$ and $17 \%$ as compared to the Pt and Ir BE devices, respectively. Likewise, $\mathrm{I}_{\text {RESET }}$ shows a decrease of $2 \%$ and $27 \%$ in the Ru BE devices in comparison to the Pt and Ir BE devices. From the device performance study, it is clear that there exists a correlation between the material property of the electrode and the RS performance metrics. In addition, the TE material has a more significant impact on the RS performance as compared the BE material. Moreover, we find that using Ta TE and Ru BE results in low current and operation voltages, while assuring compatibility with CMOS standard processes.

In order to gain insights into the effect of different electrode materials on the RS parameters of $\mathrm{Ta}_{2} \mathrm{O}_{5^{-}}$ based memory devices, we perform TEM and EDX analysis on the respective $\mathrm{TE} / \mathrm{Ta}_{2} \mathrm{O}_{5} / \mathrm{Pt}$ and $\mathrm{Ta} / \mathrm{Ta}_{2} \mathrm{O}_{5} / \mathrm{BE}$ devices that were subjected to electroforming and 50 consecutive bipolar switching cycles. Figs. 3(a)-3(c) show the EDX line profiles for the $\mathrm{TE} / \mathrm{Ta}_{2} \mathrm{O}_{5} / \mathrm{Pt}$ structure in the device switching areas with $\mathrm{Ta}, \mathrm{Cr}$ and $\mathrm{Ge}$ as the TE, respectively. The data within the delineated $\mathrm{Ta}_{2} \mathrm{O}_{5-\mathrm{x}}$ region provides the Ta and $\mathrm{O}$ compositions such that a ratio of Ta to $\mathrm{O}$ can be obtained and is depicted for each $\mathrm{TE} / \mathrm{Ta}_{2} \mathrm{O}_{5} / \mathrm{Pt}$ 
configuration (Figs. 3(a)-3(c)). Analysis of the EDX line profiles and the Ta to O ratios clearly shows that different TE materials scavenge oxygen from the amorphous $\mathrm{Ta}_{2} \mathrm{O}_{5}$ thin film at different degrees. We find that the Ta to $\mathrm{O}$ ratio is almost 1 to 1 for the Ta TE device, which strongly suggests that Ta scavenges the most oxygen ions from the $\mathrm{Ta}_{2} \mathrm{O}_{5}$ and that the oxygen vacancy concentration is the highest amongst the three $\mathrm{TE} / \mathrm{Ta}_{2} \mathrm{O}_{5} / \mathrm{Pt}$ devices. On the other hand, near-stoichiometric $\mathrm{Ta}_{2} \mathrm{O}_{5}$ layers remain in the structures with $\mathrm{Cr}$ and $\mathrm{Ge}$ TEs, indicating that both $\mathrm{Cr}$ and $\mathrm{Ge}$ have weaker oxygen scavenging ability than $\mathrm{Ta}$, which is expected since the standard free energies of oxide formation for $\mathrm{Cr}$ and Ge are higher than that of $\mathrm{Ta}^{28}$ This is also supported by our first-principle calculations which consider other factors such as the oxygen chemical potential and the defect formation energy, as will be discussed shortly. It can be inferred that the Ta TE cells have the highest $\mathrm{V}_{\mathrm{O}}$ concentrations or the largest top $\mathrm{V}_{\mathrm{O}}$ reservoirs near the $\mathrm{TE} / \mathrm{Ta}_{2} \mathrm{O}_{5}$ interface, followed by $\mathrm{Cr}$ and then $\mathrm{Ge}$.

Similarly, EDX is also employed to characterize the $\mathrm{Ta} / \mathrm{Ta}_{2} \mathrm{O}_{5} / \mathrm{BE}$ structures with $\mathrm{Ru}$, $\mathrm{Pt}$, and Ir as $\mathrm{BE}$. It is clear from Figs. 4(a)-4(c) that similar Ta to $\mathrm{O}$ ratios are obtained due to minimal oxygen scavenging by the BE materials. To obtain a quantitative comparison, we normalized the distance and aligned each EDX profile with regards to the intersection between the respective BE and $\mathrm{O}$ signals, then we suggest that the interfacial layer (IL) at the $\mathrm{BE} / \mathrm{Ta}_{2} \mathrm{O}_{5}$ interface can be estimated using the $10-80 \%$ of the $\mathrm{BE}$ line profile. It is found that the BE IL thickness increases when the BE changes from Ir to Pt to $\mathrm{Ru}$. These ILs may serve as bottom $\mathrm{V}_{\mathrm{O}}$ reservoirs which further reduces the operation power by maintaining an asymmetric $\mathrm{V}_{\mathrm{O}}$ filament structure. ${ }^{29}$

To obtain more accurate derivations of the Schottky barrier height, $\Phi_{b}$, at the $\mathrm{BE} / \mathrm{Ta}_{2} \mathrm{O}_{5}$ interface, we will need to account for the Fermi-level pinning at the interface. Due to the formation of the interface dipole, the metal Fermi level tends to align to the charge neutrality level, $\Phi_{\mathrm{CNL}}$ of the $\mathrm{Ta}_{2} \mathrm{O}_{5}$ layer, which causes the effective metal work function, $\Phi_{\text {eff, }}$, to differ from the vacuum metal work function, $\Phi_{\text {vac. }}{ }^{30-34}$ The $\Phi_{\text {eff }}$ of the BE materials can be calculated based on equation (1) below: ${ }^{35}$ 


$$
\Phi_{e f f}=\Phi_{C N L}+S\left(\Phi_{v a c}-\Phi_{C N L}\right)
$$

where $\Phi_{C N L}=3.1 \mathrm{eV}^{36}, \mathrm{~S}=0.49^{36}$ and $\Phi_{\text {vac }}(\mathrm{Ru}=4.71, \mathrm{Pt}=5.12, \mathrm{Ir}=5.76)^{28}$. Thus, the $\Phi_{\text {eff }}$ values of the $\mathrm{Ru}, \mathrm{Pt}$, and Ir with respect to the $\mathrm{Ta}_{2} \mathrm{O}_{5}$ are $3.89 \mathrm{eV}, 4.09 \mathrm{eV}$, and $4.40 \mathrm{eV}$, respectively. Then, we calculate the $\Phi_{b}$ using the following equation (2):

$$
\Phi_{b}=\Phi_{e f f}-\chi
$$

where $\chi$ is the oxygen affinity of $\mathrm{Ta}_{2} \mathrm{O}_{5}=3.2 \mathrm{eV}$. Hence, we can derive the $\Phi_{b}$ values of the Ru, Pt, and Ir with respect to the $\mathrm{Ta}_{2} \mathrm{O}_{5}$ to be $0.69 \mathrm{eV}, 0.89 \mathrm{eV}$, and $1.2 \mathrm{eV}$, respectively. Fig. $4 \mathrm{~d}$ shows the band diagram where the $\Phi_{b}$ at the $\mathrm{BE} / \mathrm{Ta}_{2} \mathrm{O}_{5}$ increases from Ru to Pt to Ir.

To obtain a microscopic insight into our results, we perform first principles calculations of the charged oxygen vacancy formation energy in the amorphous $\mathrm{Ta}_{2} \mathrm{O}_{5}$ with the different electrode materials. The simulation parameters that are used here are similar to our previous work. ${ }^{38} \mathrm{We}$ can use the scavenger electrode to set the $V_{O}$ formation energy, $E_{\text {form}}$, in the RRAM devices. This occurs because $\mathrm{E}_{\text {form }}$ at any arbitrary oxygen chemical potential, $\mu_{1}$, is given by equation (3):

$$
E_{\text {form }}\left(\mu_{1}\right)=E_{\text {form }}(0)+\mu_{1}
$$

where $\mathrm{E}_{\text {form }}(0)$ is the vacancy formation energy at $\mu_{\mathrm{O}}=0 \mathrm{eV}$. Therefore, we can increase the formation energy of the $V_{O}$ by raising the $\mu_{O}$ with oxygen-scavenging materials that are more electronegative than the parent metal. The trend is illustrated in Fig. 5(a). By selecting a metal with low electronegativity as the TE material, the $\mathrm{E}_{\text {form }}$ can be reduced as indicated by our Ta TE, which has the lowest electronegativity and $\mathrm{E}_{\text {form }}$. On the other hand, highest $\mathrm{E}_{\text {form }}$ is obtained with Ir BE due to Ir having the highest electronegativity among the $\mathrm{BE}$ materials. The $\mathrm{V}_{\mathrm{O}}$ concentration is inversely proportional to the $\mathrm{E}_{\text {form}}$. Lower $\mathrm{E}_{\text {form }}$ leads to higher $\mathrm{V}_{\mathrm{O}}$ concentration. Clearly, the TE materials possess lower electronegativities than the BE materials and such the TE materials have stronger influence over the RS 
parameters as is observed in the device performance study. Therefore, we can tune the $\mathrm{V}_{\mathrm{O}}$ concentration by using different electrode materials with different electronegativities. Based on the experimental device trends, EDX results and the simulation analysis, we propose $V_{O}$ distribution profiles in the $\mathrm{TE} / \mathrm{Ta}_{2} \mathrm{O}_{5} / \mathrm{Pt}$ and $\mathrm{Ta} / \mathrm{Ta}_{2} \mathrm{O}_{5} / \mathrm{BE}$ structures (Figs. 5(b)-5(c)). It is worthwhile to point out that both the TE and BE will affect the oxygen chemical potential such that the oxygen chemical potential, and therefore the $\mathrm{V}_{\mathrm{O}}$ concentration will have a distribution in the device, determined by the two electrodes, as shown in Figs. 5(b)-(c). High $V_{O}$ concentration is found at the top $V_{O}$ reservoir due to the strong oxygenscavenging effect of TE materials. The highest $\mathrm{V}_{\mathrm{O}}$ level exists in $\mathrm{Ta} / \mathrm{Ta}_{2} \mathrm{O}_{5} / \mathrm{Pt}$ structure, followed by the $\mathrm{Cr} / \mathrm{Ta}_{2} \mathrm{O}_{5} / \mathrm{Pt}$ and lastly $\mathrm{Ge} / \mathrm{Ta}_{2} \mathrm{O}_{5} / \mathrm{Pt}$. Conversely, lower $\mathrm{V}_{\mathrm{O}}$ concentration is found at the bottom $\mathrm{V}_{\mathrm{O}}$ reservoir. Moreover, a continuous $\mathrm{V}_{\mathrm{O}}$ concentration gradient exists within the $\mathrm{Ta}_{2} \mathrm{O}_{5}$ region.

By combining the electrical performance, the chemical composition characterization, and the firstprinciple simulations, we propose a unified model (Fig. 6) for oxide-based RRAM electrode design that can be elucidated using the $V_{O}$ migration induced oxygen-deficient conduction filament RS mechanism. 6,39-40 The main role of the TE is to create a skewed $\mathrm{V}_{\mathrm{O}}$ distribution in the $\mathrm{Ta}_{2} \mathrm{O}_{5}$, where there is a large $\mathrm{V}_{\mathrm{O}}$ concentration near the $\mathrm{TE} / \mathrm{Ta}_{2} \mathrm{O}_{5}$ interface. This agglomeration of $\mathrm{V}_{\mathrm{O}}$ benefits the RS by serving as a reservoir to facilitate the $\mathrm{V}_{\mathrm{O}}$ exchange during the SET and RESET processes. We find that when using the more chemically active Ta TE, more oxygen ions are scavenged from the $\mathrm{Ta}_{2} \mathrm{O}_{5}$ and the $\mathrm{E}_{\text {form }}$ is reduced, which increases the $\mathrm{V}_{\mathrm{O}}$ concentration near the $\mathrm{Ta} / \mathrm{Ta}_{2} \mathrm{O}_{5}$ interface, thus facilitating the filamentary formation, resulting in significant reductions in the operation voltages, especially the $\mathrm{V}_{\text {SET }}$. On the other hand, with a less chemically reactive $\mathrm{TE}$ such as $\mathrm{Cr}$ and $\mathrm{Ge}$, less oxygen ions will be scavenged from the $\mathrm{Ta}_{2} \mathrm{O}_{5}$ film, thus the $\mathrm{Ta}_{2} \mathrm{O}_{5}$ films are almost stoichiometric. As predicted by the $\mathrm{ab}$ initio calculations, $\mathrm{Cr}$ and $\mathrm{Ge}$ TEs increases the $\mathrm{E}_{\text {form }}$, translating to less $\mathrm{V}_{\mathrm{O}}$ being produced at the $\mathrm{Cr} / \mathrm{Ta}_{2} \mathrm{O}_{5}$ and $\mathrm{Ge} / \mathrm{Ta}_{2} \mathrm{O}_{5}$ interfaces, thus higher operation voltages are observed. 
The $\mathrm{BE}$ creates an IL or bottom $\mathrm{V}_{\mathrm{O}}$ reservoir that contains a concentration of $\mathrm{V}_{\mathrm{O}}$ much lower than that of the top $V_{O}$ reservoir. Due to the bottom $V_{O}$ reservoir and the large work functions of the $\mathrm{BE}$ material, a Schottky barrier will be formed at the $\mathrm{BE} / \mathrm{Ta}_{2} \mathrm{O}_{5}$ interface. ${ }^{36,41-43}$ In general, the $\Phi_{\mathrm{b}}$ is inversely proportional to the $\mathrm{V}_{\mathrm{O}}$ concentration. ${ }^{43}$ As shown by our model in Fig. 6, changing the Pt BE to the CMOS-compatible Ru increases the IL thickness and decreases the $\Phi_{\mathrm{b}}$, thus reducing the $\mathrm{V}_{\text {RESET }}$ in the $\mathrm{Ru} \mathrm{BE}$ devices. In addition, the $\mathrm{E}_{\text {form }}$ is reduced when $\mathrm{Ru}$ is employed as the $\mathrm{BE}$, which increases the $V_{O}$ concentration and the bottom $V_{O}$ reservoir capacity. Since the RRAM device can be regarded as a series connection of a cell resistance and a load resistance where the latter may be attributed to the IL, the increasing $\mathrm{I}_{\text {RESET }}$ when $\mathrm{BE}$ is changed from $\mathrm{Ru}$ to Ir may be due to the decreasing load resistance as a result of the reduction in the IL thickness. Hence, the proper choice of electrode materials for a given RS oxide can lead to the generation of an appropriate concentration of $\mathrm{V}_{\mathrm{O}}$, thus benefitting the formation of $\mathrm{CF}$ and the RS performance.

Considering the above results and discussions of $\mathrm{Ta}_{2} \mathrm{O}_{5}$-based RRAM memory, we suggest two main rules for the electrode selection. Firstly, the TE material should have low $E_{\text {form }}$ and an oxygenscavenging ability similar to the host metal of the oxide memory layer to create a large top $\mathrm{V}_{\mathrm{O}}$ reservoir that reduces the operation voltages and current. For example, $\mathrm{Hf}$ is usually the preferred TE for $\mathrm{HfO}_{2}$ based memory device, ${ }^{5}$ while the TE for $\mathrm{TiO}_{2}$ based RRAM is either $\mathrm{Ti}$ or $\mathrm{Al}^{44}$ As for $\mathrm{TaO}_{\mathrm{x}}$ based RRAM, Ti and Ta are generally chosen for the TE to achieve superior memory performance such as long endurance and fast switching. ${ }^{2,17}$ Secondly, the BE material should have a moderately high $\mathrm{E}_{\text {form }}$ such that a bottom $\mathrm{V}_{O}$ reservoir exists to create an asymmetry in the $\mathrm{V}_{\mathrm{O}}$ distribution between both electrodes. In this work, as experimentally and theoretically demonstrated, the best candidates for TE and $\mathrm{BE}$ in a $\mathrm{Ta}_{2} \mathrm{O}_{5}$ memory device are $\mathrm{Ta}$ and $\mathrm{Ru}$, respectively.

\section{CONCLUSION}


In summary, we provide a comprehensive experimental and theoretical study on the impact of the electrode materials on the RS characteristics in $\mathrm{Ta}_{2} \mathrm{O}_{5}$-based RRAM devices, as a general framework for electrode material selection in oxide-based memories. The EDX results show that oxygen ions are scavenged by the various electrode materials in different degrees, resulting in different $V_{O}$ concentrations in the $\mathrm{Ta}_{2} \mathrm{O}_{5}$ memory layer. More oxygen ions are scavenged by the $\mathrm{Ta} \mathrm{TE}$ as compared to the $\mathrm{Cr}$ and Ge TEs based devices, which facilitated the filamentary processes, resulting in lower operation voltages and current. Replacing the $\mathrm{Pt} \mathrm{BE}$ with $\mathrm{Ru}$ further reduces the power consumption while ensuring CMOS compatibility. The first principles methods verify both EDX and device performance results by revealing that the electrode material tunes the oxygen chemical potential and $V_{O}$ formation energy to control the $\mathrm{V}_{\mathrm{O}}$ concentration in the $\mathrm{Ta}_{2} \mathrm{O}_{5}$ switching layer, leading to the observed trends in the device performance metrics. Hence, the selection of certain CMOS-compatible electrode materials for a given RS oxide can lead to the generation of a specific $\mathrm{V}_{\mathrm{O}}$ concentration that optimizes the RS parameters in future applications. 


\section{REFERENCES}

1 C. Ho, C.-L. Hsu, C.-C. Chen, J.-T. Liu, C.-S. Wu, C.-C. Huang, C. Hu, and F.-L. Yang, Tech. Dig. Int. Electron Devices Meet. 436 (2010).

2 A.C. Torrezan, J.P. Strachan, G. Medeiros-Ribeiro, R.S. Williams, Nanotechnology 22, 485203 (2011).

3 A.Wedig, M. Luebben, D.-Y. Cho, M. Moors, K. Skaja, V. Rana, T. Hasegawa, K. K. Adepalli, B. Yildiz, R. Waser, and I. Valov, Nat. Nanotechnol. 11, 67 (2016).

4 C.H. Cheng, C.Y. Tsai, A. Chin, F.S. Yeh, Tech. Dig. Int. Electron Devices Meet. 448 (2010).

5 B. Govoreanu, G.S. Kar, Y.-Y. Chen, V. Paraschiv, S. Kubicek, A. Fantini, I.P. Radu, L. Goux, S. Clima, R. Degraeve, N. Jossart, O. Richard, T. Vandeweyer, K. Seo, P. Hendrickx, G. Pourtois, H. Bender, L. Altimime, D.J. Wouters, J.A. Kittl, and M. Jurczak, Tech. Dig. Int. Electron Devices Meet. 729 (2011).

6 F. Pan, S. Gao, C. Chen, C. Song, and F. Zeng, Materials Science and Engineering R. 83, 1 (2014).

7 A. Sawa, Mater. Today 11, 28 (2008).

8 R. Waser, R. Dittmann, G. Staikov, and K. Szot, Adv. Mater. 21, 2632 (2009).

9 C.-Y. Lin, C.-Y. Wu, C.-Y. Wu, T.-C. Lee, F.-L. Yang, C. Hu, and T.-Y. Tseng, IEEE Electron. Device Lett. 28, 366 (2007).

10 C.B. Lee, B. S. Kang, A. Benayad, M. J. Lee, S.-E. Ahn, K. H. Kim, G. Stefanovich, Y. Park, and I. K. Yoo, Appl. Phys. Lett. 93, 042115 (2008).

11 H. Y. Jeong, S. K. Kim, J. Y. Lee, and S.-Y. Choi, J. Electrochem. Soc. 158, H979 (2011). 
12 K.-L. Lin, T.-H. Hou, J. Shieh, J.-H. Lin, C.-T. Chou, and Y.-J. Lee, J. Appl. Phys. 109, 084104 (2011).

13 L. Goux, A. Fantini, A. Redolfi, C. Y. Chen, F. F. Shi, R. Degraeve, Y. Y. Chen, T. Witters, G. Groeseneken, and M. Jurczak, VLSI Symp. Tech. Dig. 162, (2014).

14 V. Y.-Q. Zhuo, Y. Jiang, R. Zhao, L. P. Shi, Y. Yang, T. C. Chong, and J. Robertson, IEEE Electron. Device Lett. 34, 1130 (2013).

15 C. Chen, S. Gao, F. Zeng, G. S. Tang, S. Z. Li, C. Song, H. D. Fu, and F. Pan, J. Appl. Phys. 114, 014502 (2013).

16 M.-J. Lee, C. B. Lee, D. Lee, S. R. Lee, M. Chang, J. H. Hur, Y.-B. Kim, C.-J. Kim, D. H. Seo, S. Seo, U.-I. Chung, I.-K. Yoo, and K. Kim, Nature Mater. 10, 625 (2011).

17 J. J. Yang, M.-X. Zhang, J. P. Strachan, F. Miao, M. D. Pickett, R. D. Kelley, G. MedeirosRibeiro, and R. S. Williams, Appl. Phys. Lett. 97, 232102 (2010).

18 S. Hong, S. H. Chang, C. Phatak, B. Magyari-Kope, Y, Nishi, S. Chattopadhyay, and J. H. Kim, ECS Transactions 69, 51 (2015).

19 J. J. Yang, D. B. Strukov, and D. R. Stewart, Nature Nano. 8, 13 (2013).

20 D. S. Jeong, R. Thomas, R. S. Katiyar, J. F. Scott, H. Kolstedt, A. Petraru, and C. S. Hwang, Rep. Prog. Phys. 75, 076502 (2012).

21 D. H. Kwon, K. M. Kim, J. H. Jang, M. Jeon, M. H. Lee, G. H. Kim, X. S. Li, G. S. Park, B. Lee, S. Han, M. Kim, and C. S. Hwang, Nat. Nanotechnol. 5, 148 (2010).

22 G. Bersuker, D. Gilmer, D. Veskler, P. Kirsch, L. Vandelli, A. Padovani, L. Larcher, K. McKenna, A. Shluger, V. Igesias, M. Porti, and M. Nafria, J. Appl. Phys. 100, 124518 (2011). 
23 Z. Wei, T. Takagi, Y. Katoh, T. Ninomiya, K. Kawai, S. Mitani, K. Katayama, S. Fujii, R. Miyanaga, Y. Kawashima, T. Mikawa, K. Shimakawa, and K. Aono, in Technical Digest IEDM (2011), p. 31.4.

24 S. Clima, Y. Y. Chen, R. Degraeve, M. Mees, K. Sankaran, B. Govoreanu, M. Jurczak, S. DeGendt, and G. Pourtois, Appl. Phys. Lett. 100, 133102 (2012).

25 S. Clima, K. Sankaran, Y. Y. Chen, A. Fantini, I. Celano, A. Belmonte, L. Goux, B. Govoreanu, R. Degraeve, D. J. Wouters, M. Jurczak, W. Vandervorst, S. DeGendt, and G. Pourtois, Phys. Status Solidi RRL 8, 501 (2014).

26 B. Magyari-Kope, S. G. Park, H. D. Lee, and Y. Nishi, J. Mater. Sci. 47, 7498 (2012).

27 E. Linn, R. Rosezin, C. Kugeler, and R. Waser, Nature Mater. 9, 403 (2010)

28 D. R. Lide, CRC Handbook of Chemistry and Physics (CRC, Boca Raton, FL, 2006).

29 R. Degraeve, A. Fantini, S. Clima, B. Govoreanu, L. Goux, Y. Y. Chen, D. J. Wouters, Ph. Roussel, G. S. Kar, G. Pourtois, S. Cosemans, J. A. Kittl, G. Groeseneken, M. Jurczak, and L. Altimime, VLSI Symp. Tech. Dig. 75 (2012).

30 Y.-C. Yeo, T.-J. King, and C. Hu, J. Appl. Phys. 92, 7266 (2002)

31 W. Monch, J. Vac. Sci. Technol. B 14, 2985 (1996).

32 V. Heine, Phys. Rev. 138, A1689 (1965).

33 S. G. Louie, and M. L. Cohen, Phys. Rev. B 13, 2461 (1976).

34 D. A. Muller, D. A. Shashkov, R. Benedek, L. H. Yang, J. Silcox, and D. N. Seidman, Phys. Rev. Lett. 80, 4741 (1998).

35 E. A. Kraut, R. W. Grant, J. R. Waldrop, and S. P. Kowalczyk, Phys. Rev. Lett. 44, 1620 (1980). 36 V. Y.-Q. Zhuo, Y. Jiang, M. H. Li, E. K. Chua, Z. Zhang, J. S. Pan, R. Zhao, L. P. Shi, T. C. Chong; and J. Robertson, Appl. Phys. Lett. 102, 062106 (2013). 
37 J. Robertson, J. Vac. Sci. Technol. B. 18, 1785 (2000).

38 Y. Guo, and J. Robertson, Appl. Phys. Lett. 105, 223516 (2014).

39 H. S. P. Wong, H.-Y. Lee, S. Yu, Y.-S. Chen, Y. Wu, P.-S.Chen, B. Lee, F. T. Chen, and M.-J. Tsai, Proc. IEEE. 100, 1951 (2012).

40 J. S. Lee, S. Lee, and T. W. Noh, App. Phys. Rev. 2, 031303 (2015).

41 A. Sawa, T. Fujii, M. Kawasaki, and Y. Tokura, Appl. Phys. Lett. 85, 4073 (2004).

42 D.-J. Seong, M. Jo, D. Lee, and H. Hwang, Electrochem. Solid State Lett. 10, H168 (2007).

43 J. J. Yang, M. D. Pickett, X. Li, D. A. A. Ohlberg, D. R. Stewart, and R. S. Williams, Nat. Nanotechnol. 3, 429 (2008).

44 X. L. Shao, L. W. Zhou, K. J. Yoon, H. Jiang, J. S. Zhao, K. L. Zhang, S. Yoo, and C. S. Hwang, Nanoscale 7, 11063 (2015). 


\section{FIGURE CAPTIONS}

FIG. 1. (a) Schematic diagram showing structure of our $\mathrm{Ta}_{2} \mathrm{O}_{5}$-based devices. The $\mathrm{TE} / \mathrm{Ta}_{2} \mathrm{O}_{5} / \mathrm{BE}$ stack is enclosed in red dotted lines.(b) HR-TEM cross-section image of the TE/ $/ \mathrm{Ta}_{2} \mathrm{O}_{5} / \mathrm{BE}$ stack. TE materials used are $\mathrm{Ta}, \mathrm{Cr}$, and $\mathrm{Ge}$ while the $\mathrm{BE}$ materials are $\mathrm{Ru}, \mathrm{Pt}$, and Ir. (c) Process flow that is used for fabrication of the devices.

FIG. 2. (a) Typical bipolar resistive switching I-V curves of our $\mathrm{Ta}_{2} \mathrm{O}_{5}$-based memory devices with Ta, $\mathrm{Cr}$, and Ge TE, respectively. (b) Average values of the DC SET and RESET voltages, and (c) DC RESET current of our TE/ $\mathrm{Ta}_{2} \mathrm{O}_{5} / \mathrm{Pt}$ devices. (d) I-V curves of the $\mathrm{Ta} / \mathrm{Ta}_{2} \mathrm{O}_{5} / \mathrm{BE}$ devices with $\mathrm{Ru}, \mathrm{Pt}$, and Ir BE, respectively. (e) Average values of the DC SET and RESET voltages, and (f) DC RESET current of our $\mathrm{Ta} / \mathrm{Ta}_{2} \mathrm{O}_{5} / \mathrm{BE}$ devices. Error bars represent the $10-90 \%$ range. For each structure, ten devices are randomly selected and each device is cycled 50 times to obtain the statistics.

FIG. 3. Normalized EDX profiles of the TE/ $/ \mathrm{Ta}_{2} \mathrm{O}_{5} / \mathrm{Pt}$ cells with (a) $\mathrm{Ta}$, (b) $\mathrm{Cr}$, and (c) Ge as TE. Ratios of the $\mathrm{Ta}$ to $\mathrm{O}$ in the $\mathrm{Ta}_{2} \mathrm{O}_{5-\mathrm{x}}$ region are depicted for each $\mathrm{TE} / \mathrm{Ta}_{2} \mathrm{O}_{5} / \mathrm{Pt}$ cell.

FIG. 4. Normalized EDX profiles of the $\mathrm{Ta} / \mathrm{Ta}_{2} \mathrm{O}_{5} / \mathrm{BE}$ cells with (a) $\mathrm{Ru}$, (b) Pt, and (c) Ir as BE. The interfacial layer (IL) thickness is determined by the $10-80 \%$ of the BE signal. (d) Energy band diagrams for the BE materials in contact with $\mathrm{Ta}_{2} \mathrm{O}_{5}$ thin film. Schottky barrier heights $\left(\Phi_{b}\right)$ of $\mathrm{Ru}, \mathrm{Pt}$, and Ir are indicated accordingly. The material on the right of each material pair is $\mathrm{Ta}_{2} \mathrm{O}_{5}$ with a bandgap of $4.4 \mathrm{eV}$ and electron affinity of $3.2 \mathrm{eV}$. 
FIG. 5. (a) Oxygen vacancy formation energies and oxygen chemical potentials of the TEs ( $\mathrm{Ta}, \mathrm{Cr}, \mathrm{Ge})$ and BEs (Ru, Pt, Ir) in contact with the amorphous $\mathrm{Ta}_{2} \mathrm{O}_{5}$. Inset: Ball-and-stick plot of the simulated amorphous $\mathrm{Ta}_{2} \mathrm{O}_{5}$ where the blue and red balls are $\mathrm{Ta}$ and $\mathrm{O}$, respectively. $(\mathrm{b}, \mathrm{c})$ Oxygen vacancy concentration profiles of the $\mathrm{TE} / \mathrm{Ta}_{2} \mathrm{O}_{5} / \mathrm{Pt}$ and $\mathrm{Ta} / \mathrm{Ta}_{2} \mathrm{O}_{5} / \mathrm{BE}$ modulated by the different TEs and BEs.

FIG. 6. Unified model for electrode materials selection shows the top and bottom oxygen vacancy reservoirs. Low $\mathrm{E}_{\text {form }} \mathrm{TE}$ with strong O-scavenging effect is preferred to create larger top oxygen vacancy reservoir capacities to reduce the operation voltages. Moderately high $\mathrm{E}_{\text {form }} \mathrm{BE}$ is preferred to create a thicker IL such that $\Phi_{\mathrm{b}}$ and thus $\mathrm{I}_{\text {RESET }}$ are reduced. Note that an asymmetry is maintained between the top and bottom oxygen vacancy reservoirs. 
(a)

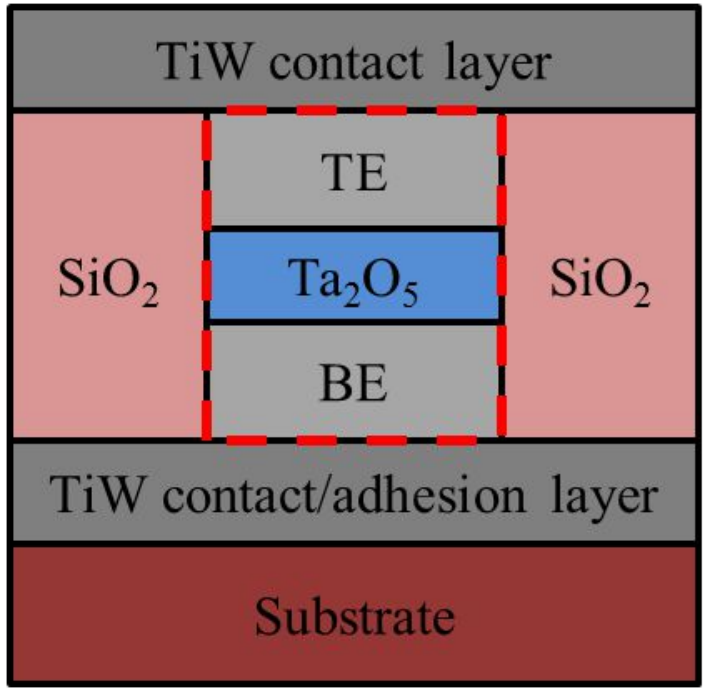

(b)

(c)

\section{Process Flow}

- TiW bottom contact formation

- $40 \mathrm{~nm}$ bottom electrode (BE) formation

- $5 \mathrm{~nm} \mathrm{Ta} \mathrm{Ta}_{2} \mathrm{O}_{5}$ memory layer formation

- $1 \mu \mathrm{m}^{2}$ active area patterning

- $\mathrm{SiO}_{2}$ passivation layer deposition

- $40 \mathrm{~nm}$ top electrode (TE) formation

$10 \mathrm{~nm}$
- TiW top contact deposition 

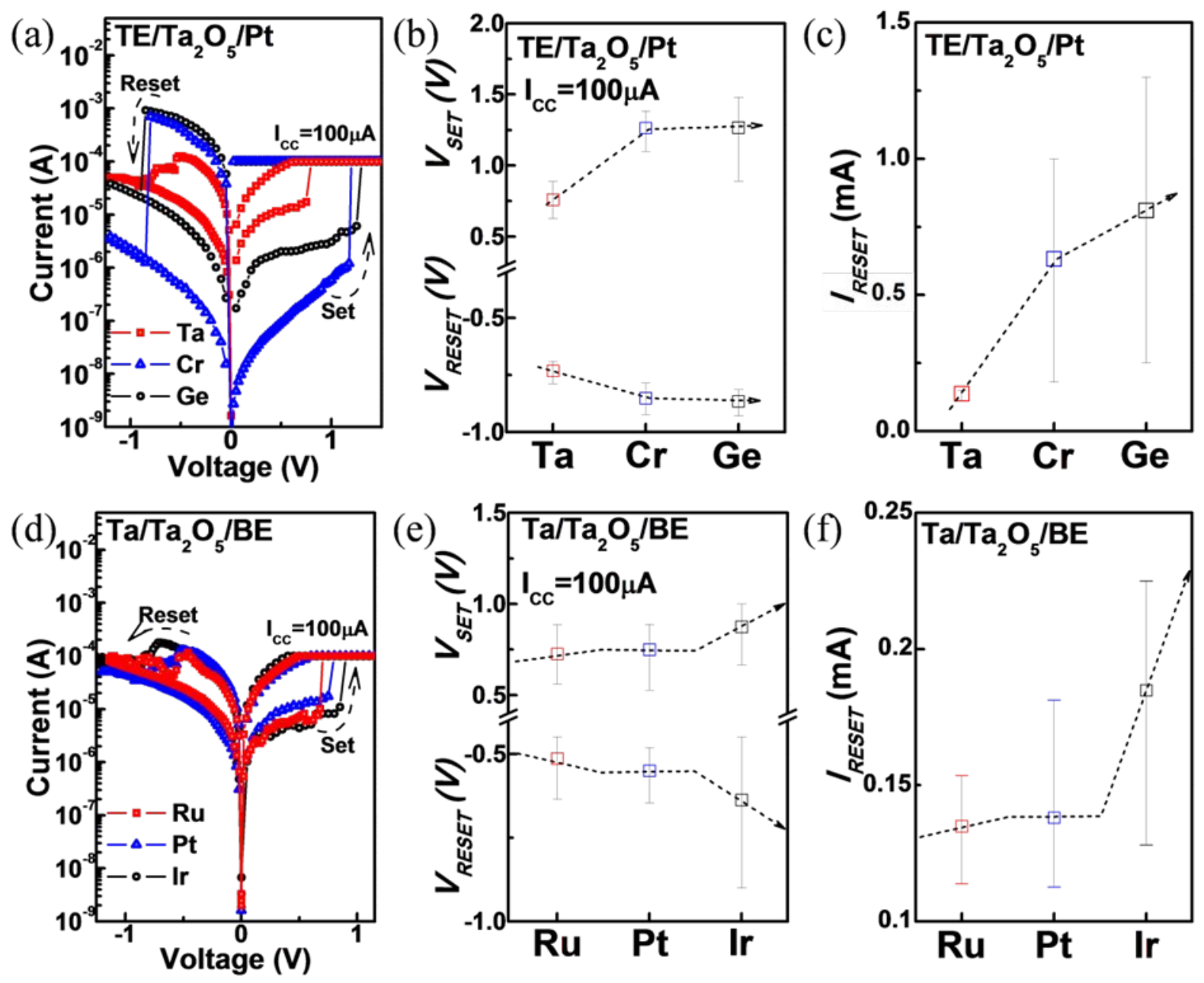

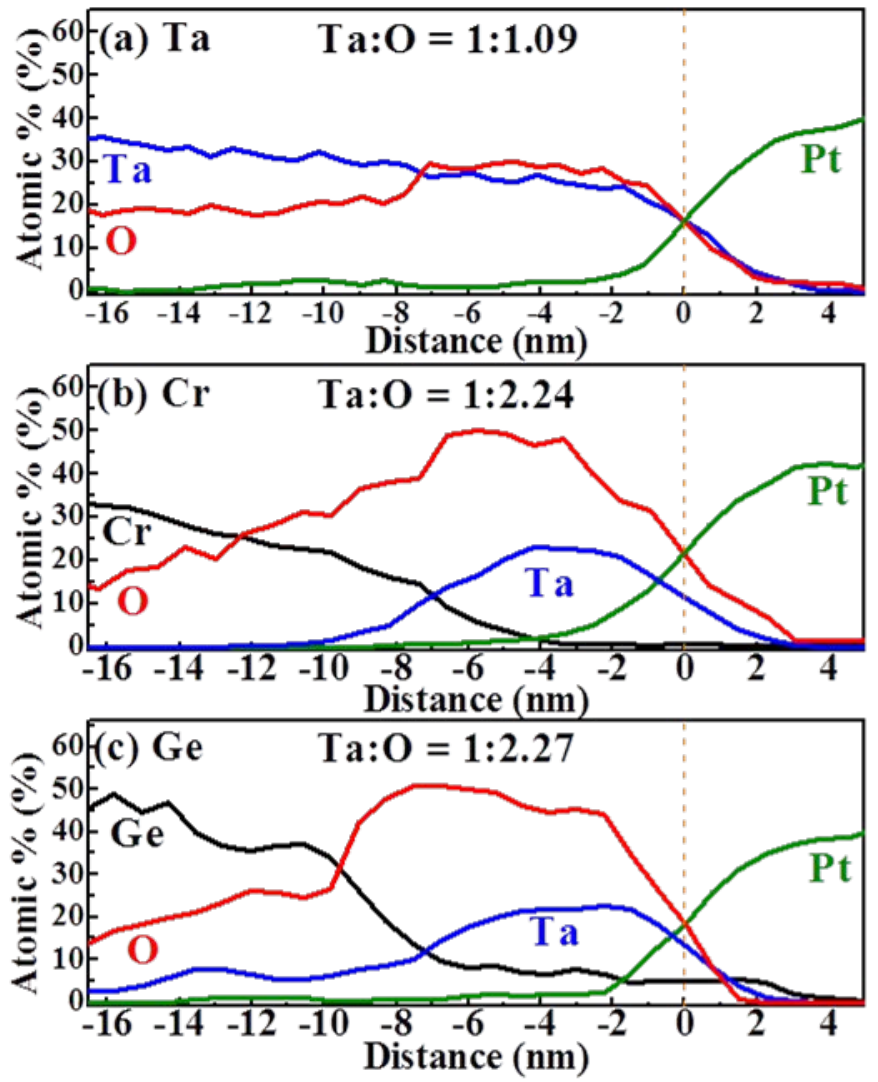

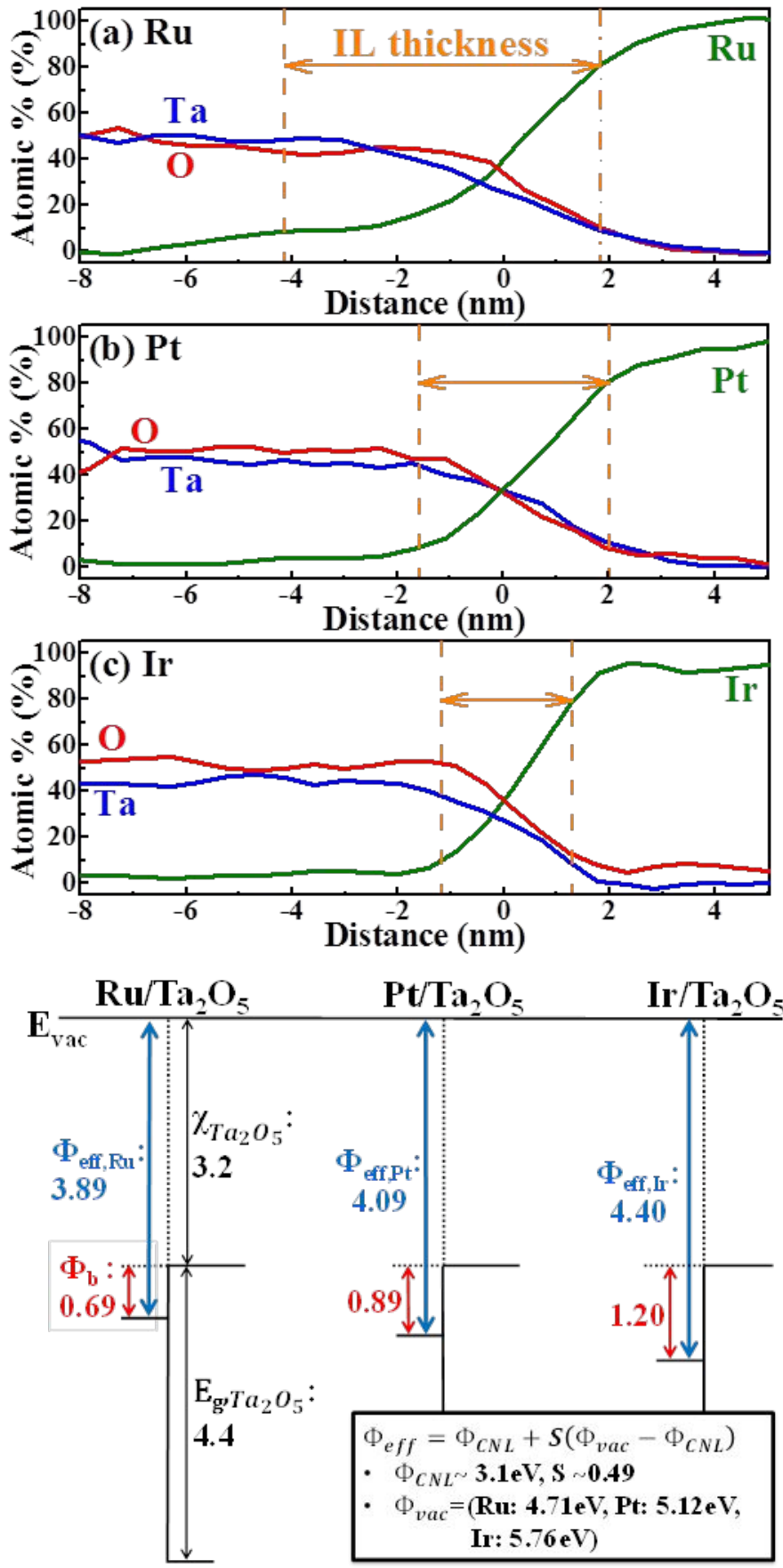


\section{Ge $\mathrm{Cr}$ Ta $\quad$ Ru Pt Ir}

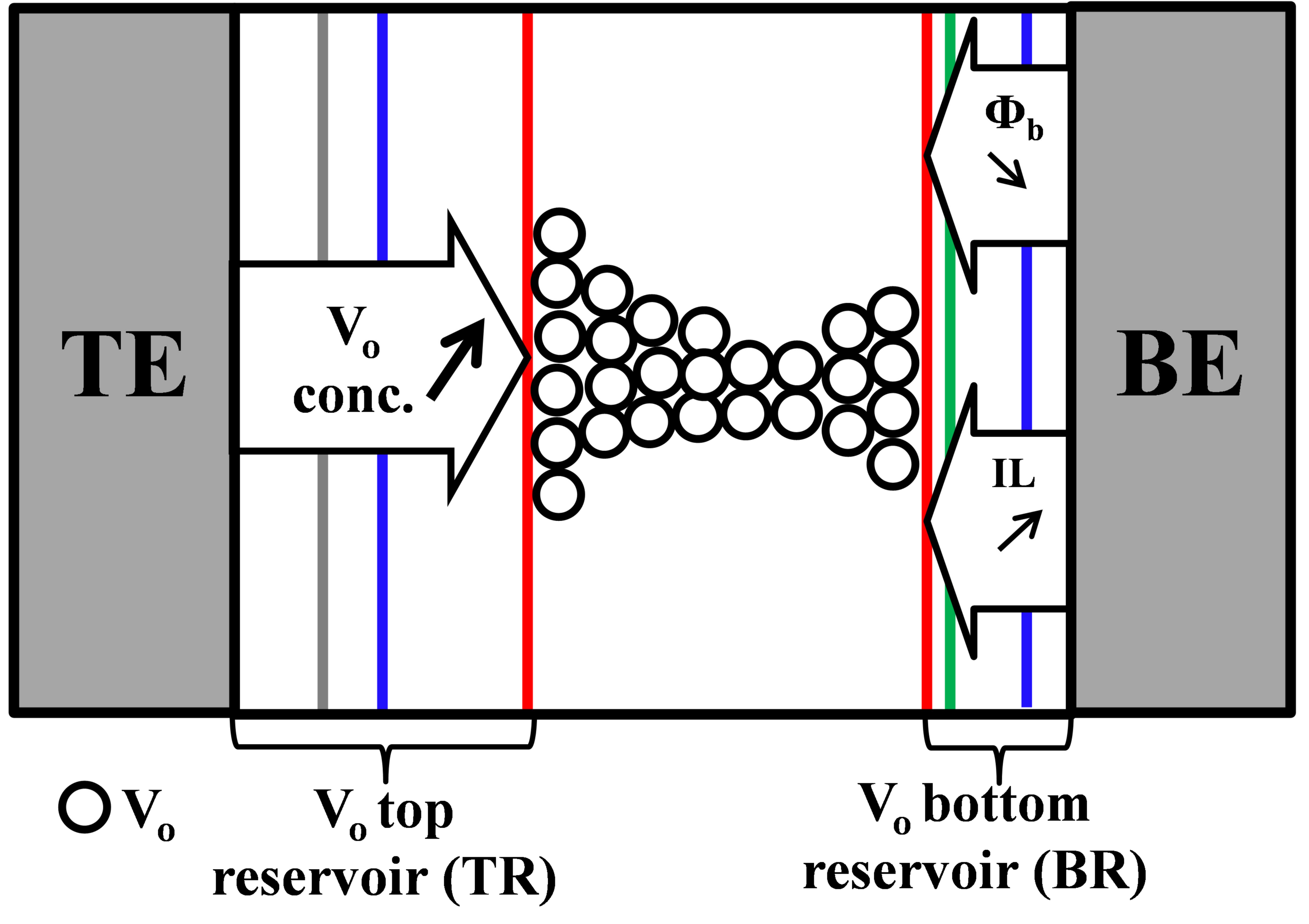

